\title{
Development of Transparent and Flexible Transistor and Analysis of its Electrical and Optical Performances
}

\author{
Abdellah Mrij, Abdelmajid EL Bakkali, Jaouad Foshi
}

\begin{abstract}
This work discusses the development of innovative transistor from intelligent thin film. A developed semiconductor junction that constitutes the core of concepted transistor is being studied. Each technology of semiconductors has shortage of some performances. The recent work is an alternative by exploiting intelligent materials to build a transistor with transparency and flexibility characteristics. Many processes are encountered during preparation of the film especially chemical deposition and exposition to laser beam to ensure dopants integration. The physical phase is a challenge for newest technology like the plasma. Thereon, we give a real example of smart thin film. The band gap is also a defiance that we are reducing to ameliorate precisely the impedance and thickness and keep at order of nanotechnology. The fabricated junctions are tested by studying their operation in ordinal conditions. We judge the quality of junctions and transistor from their optical properties and electrical ones. Moreover, we analyze evolutions of electrical impedance in function of temperature and optical reflection coefficient.
\end{abstract}

Keywords: Reflection Coefficient, Laser Beam, Electric Impedance, Transistor, Flexibility.

\section{INTRODUCTION}

$$
\mathrm{T}
$$

The recent technology is very promising thanks to smart devices especially from transistor thin-film fabrication. Indeed, it constitutes the base of electronic memory and liquid crystal display manufacturing. Above, it is very fruitful on other fields like production of energy using photovoltaic and remote control of systems [1]. In this work the established alloy contains in rich these elements $(\mathrm{PbCl} 2, \mathrm{ZnO})$. Thereon, this compound is an insulator element where we change the conductivity to get adequate junction by result innovative transistor. The intrinsic properties of our substrate are being handled using both by thermal process and exposition to laser beam. Moreover, the impurities are available so the doping process is easy to be applied. The products of recent technology have many limits and inconvenient of problems

Revised Manuscript Received on December 15, 2019

* Correspondence Author

Abdellah Mrij*, Team Electronics, Instrumentation and Measurement, Department of Physics, Faculty of Sciences and Techniques, University Moulay Ismail, BP 509, Boutalamine, Errachidia, Morocco. Email: mrijabdellah@gmail.com

Abdelmajid EL Bakkali, Team Electronics, Instrumentation and Measurement, Department of Physics, Faculty of Sciences and Techniques, University Moulay Ismail, BP 509, Boutalamine, Errachidia, Morocco.

Jaouad Foshi, Team Electronics, Instrumentation and Measurement, Department of Physics, Faculty of Sciences and Techniques, University Moulay Ismail, BP 509, Boutalamine, Errachidia, Morocco. due glazing and blazing and difficulties of hard steps during preparation. The aim process of semiconductor is based on the quality of used substrate and nature of impurities used to adjust band gap and charge carrier density [2]. According to literature the implemented materials properties and their compositions have deep influence on the performances of a given hybrid alloy, thereon the dopants are very significant [3]. Various techniques are being adopted for thin film building and semiconductors manufacturing processes either physical or chemical such as deposition techniques and laser deposition [4]. In this work we base on chemical evaporation and laser beam exposition to ensure high quality of the thin film. Moreover, the performances that we are looking are transparency and flexibility characteristics. The impurities are from promising elements that are copper and fluorite from Atlas Region in Morocco $(\mathrm{Cu}$ and $\mathrm{F})$. The objective is to improve conductivity and reduce electrical impedance. Above, the obtained phase is very challenging to old integrated elements in thin films according to the literature [5]. Many researches are being done in nanotechnologies, to resolve shortage due to smashing and bad quality of optical properties and chemical ones [6-8]. Therefore, this work is among solutions to improve optical and morphological intrinsic properties of the studied substrate [9]. We fabricate samples of semiconductor junction from developed thin film and we analyze their performances especially flexibility and transparency. Therefore, we get desired band gap that restrict electrical impedance and ensure stability during temperature variations. Above to integrate the dopants impurities we exploit exposition to laser beam because it is suitable for concepted thin film [10]. Finally, the samples are being compared to existed thin films as referred to many references $[11,12]$. From getted junctions we realize our developed transistor which is a fruitful contribution for semiconductor nanotechnology.

\section{EXPERIMENTATION PROCESS}

The developed thin film is a promising result for nanotechnology progressing. The improvement of optical and morphological characteristics is reached after preparation of samples. The thickness of thin-film is very privileged and it is at order of nanotechnology requirements. The built substrate from intelligent materials has dimensions of few nanometers. Moreover, the concepted junction is wonderful by analyzing its side optically thanks to performances of integrated material especially copper, 
fluorine and plomb. Thereon, we benefit from their characteristics to build suitable thin film junction with appropriate characteristics. The solubility of these materials in diluted acid is suitable to obtain suitable adsorption in the substrate precisely by using laser beam. Indeed, the acid medium is preferred while we want to make the erosion of substrate. Thereby, the mobility is ameliorated by result the suitable conductivity is obtained due doping diffusion that generates electron-holes $[13,14]$ that are required for conduction. However, during this fabrication process many holdbacks and difficulties phenomena are encountered due crystallization and oxidation. Therefore, to minimize these nocuous effects we adjust the chemical composition and temperature of baking. The concepted junction are working very well directly after preparation with high performances thereon we should get stability of these performances. The aim is to keep properties that ensure high performances whatever the variations of ambient conditions more specifically the temperature. The lead $(\mathrm{Pb})$ is included in $\mathrm{Si}$, $\mathrm{Ge}, \mathrm{Sn}$ and $\mathrm{C}$ family group, so it is wanted for various uses. Therefore, the semiconductors based on these elements are characterized by low potential and adequate band gap after doping process. We use this element under its derivative $\mathrm{PbCl} 2$ but with weak ratio to minimize toxic effect due chlore element. However the $\mathrm{ZnO}$ is used almost in latest techniques of semiconductors fabrication. It is an inorganic compound, insoluble in water, and it has used as a large additive in numerous materials and products including plastics and glass [15]. Although, it is abundant naturally as the form of mineral zincite but most of the zinc oxides are produced synthetically [16]. These alloys have a wide-bandgap semiconductor of the II-VI semiconductor group. By adding impurities of aluminum and the privilege of native doping the semiconductor has tendency into n-type due to oxygen and fluorine elements due their electronegativity [17]. This work has the aim to get transparency, flexibility, high electron mobility like the principle in liquid crystal displays, and electronics as thin-film transistors and light emitting diodes. The chemical deposition processes for thin film growth are described in the Fig. 1.

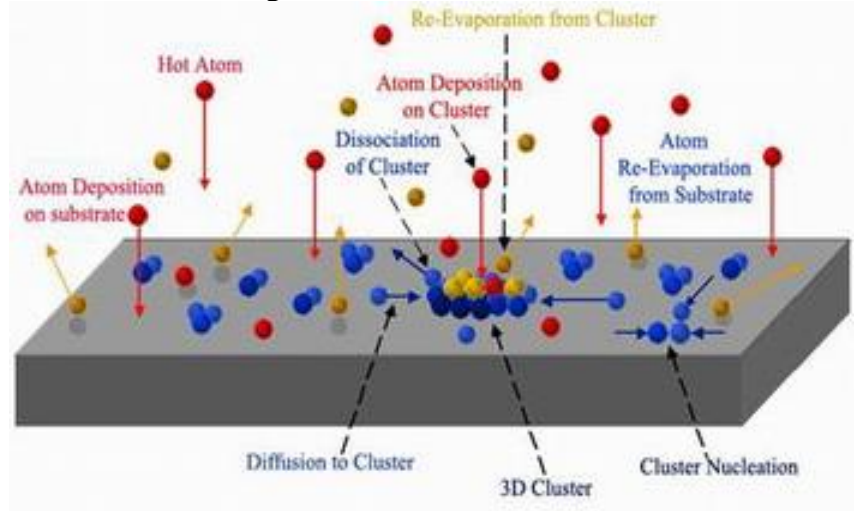

Fig.1.Thin film growth

The goal of this work is to boost performances of existing thin films by getting transparency and flexibility properties with the manufacturing scale. The core of idea is based on changing the phase such as the built of some alloys referred to the literature $[18,19]$. The aluminum $(\mathrm{Al})$ is also used to reduce doping of substrate as mask in other technology of thin film manufacturing. After many tests we adopt the mixture of $\mathrm{PbCl} 2$ and $\mathrm{ZnO}$ to obtain suitable substrate. In fact, this is very significant during measurement of electric impedance and optical reflection coefficient using laser source emitter and receiver. We look to boost transparency character but without negative influence on electrical properties. Thereon, the reflection coefficient should decrease with quality of fabricated junction from thin film. This in one hand, in other hand the improvement of junction film must ensure weak electric impedance. The thin layer of the mixture is exposed to the laser beam with its two sides to make easy the doping process. The exposition to laser beam is applied for $10 \mathrm{~min}$. After that the compound is placed in the oven where we will make doping of each face by chemical evaporation. The p-type side is obtained using copper ions but the n-type has been gotten by implementation of fluorine ions. The fabrication of this junction doesn't require high temperature for diffusion process so we use the oven that reaches $480 \mathrm{C}^{\circ}$. By result the transparent and flexible semiconductor junction is obtained with different performances according to the quantity of impurities. As result our thin film is obtained. The impedance was calculated for various temperatures to confirm the accepted performances of this alloy film as done in previous and similar works referring to the literature [20, 21]. The illustration of fabricated film is given by the following figure.

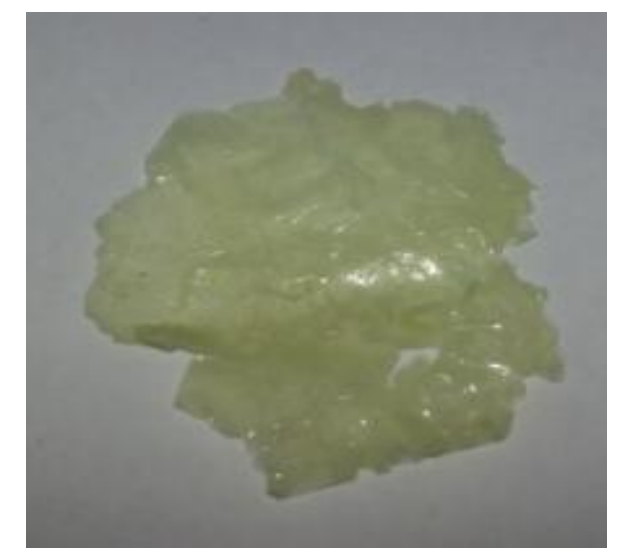

Fig. 2. Developed transparent and flexible thin film.

The result of conception is very significant thanks to transparency and flexibility of thin film obtained. The electrical impedance depends on chemical composition so we adjust the quantities of impurities during doping process. To test transparency and flexibility we base on optical reflection coefficient to a special laser beam.

\section{RESULTS AND DISCUSSION}

The fabricated specimens are noted A, B, C and D to make easy their comparison. We considerate $\mathbf{V}_{\mathbf{t}}$ the total volume used of $\mathrm{PbCl}_{2}$ and $\mathrm{ZnO}$ above that their concentrations are fixed at $0.5 \mathrm{~mol} / \mathrm{L}$ to prepare the thin film. So the material composition of dopants $\mathrm{Cu}^{2+}$ and $\mathrm{F}^{-}$is obtained by dividing the volume of each one on total volume $\mathbf{V}_{\mathbf{t}}$. For the concentration of solutions used for these dopants we adjust it at order of $0.5 \mathrm{~mol} / \mathrm{L}$. We resume results in the table as shown below for each dopant and we measure the electrical impedance at ambient temperature. 
Table- I: Chemical composition of impurities and Resistance at $\left(t=25 C^{\circ}\right)$.

\begin{tabular}{|cccc|}
\hline $\begin{array}{l}\text { Sample } \\
\left(\mathrm{K} \Omega / \mathrm{cm}^{\wedge} 2\right)\end{array}$ & $\mathrm{Cu}^{2+(}$ at.\%) & $\mathrm{F}^{-}$(at.\%) & $\mathrm{R}$ \\
\hline $\mathrm{A}$ & 10 & 10 & 2725 \\
\hline $\mathrm{B}$ & 18 & 18 & 2432 \\
\hline $\mathrm{C}$ & 24 & 24 & 1936 \\
\hline $\mathrm{D}$ & 36 & 36 & 1525 \\
\hline
\end{tabular}

The global volume $\mathbf{V}_{\mathbf{t}}$ of prepared thin film junction permits to determine the composition ratio. Thereby, we calculate the rate of each volume for $\mathrm{PbCl}_{2}$ and $\mathrm{ZnO}$ reporting to the total volume $\mathbf{V}_{\mathbf{t}}$ as given in the following table.

Table- II: Chemical composition ratios of fabricated specimens.

\begin{tabular}{|lcc|}
\hline $\begin{array}{l}\text { Composition } \\
\text { Ratio (\%) }\end{array}$ & $\mathrm{PbCl}_{2}$ & $\mathrm{ZnO}$ \\
\hline A & 35 & 23 \\
\hline B & 73 & 19 \\
\hline C & 33 & 75 \\
\hline D & 50 & 50 \\
\hline
\end{tabular}

According to the table, we remark the influence of specimen composition on the electrical performances, optical and morphological properties. For the sample $\mathrm{A}$ the $\mathrm{PbCl} 2$ and $\mathrm{ZnO}$ are with weak ratios above that doping impurities are poor so the impedance is important around $2725 \mathrm{~K} \Omega$. However for $\mathrm{B} \mathrm{PbCl} 2$ is important and low quantity of $\mathrm{ZnO}$ is used the influence is noted of decreasing the gap with accepted quantity of impurities. While for the specimen $\mathrm{C}$ the $\mathrm{ZnO}$ is higher and more concentrations of doping elements are used to get low electrical impedance of junction. Finally the specimen $\mathrm{D}$ is characterized by desired band gap when $\mathrm{PbCl} 2$ and $\mathrm{ZnO}$ are used equally in parallel with increasing impurities of doping, as results the suitable semiconductor junction is reached. Moreover, each sample is analyzed using laser beam reflection process among many analysis methods $[22,23]$. In our case the laser diode used is excluded from DVD reader laser to determine ratios of reflected and absorbed voltages to analyze the quality of transparency characteristic. By calculation of voltage ratio, the reflectance data was obtained which is one of the optical properties [24, 25] and illustrate in Fig. 4 and sum up the data in Table 3. For a given laser emitter that works by $5 \mathrm{~V}$ we calculate reflected voltage by putting the specimen on polycarbonate layer and inserting it in the DVD reader. Thereon, the reflection coefficient is measured by dividing two voltages.

Table- III: Reflection coefficient of concepted junctions

\begin{tabular}{|lcc|}
\hline Sample ID & $\begin{array}{c}\text { Reflected Voltage } \\
(\mathrm{mV})\end{array}$ & $\begin{array}{c}\text { Reflection coefficient } \\
(\%)\end{array}$ \\
\hline A & 250 & 4.92 \\
\hline B & 189 & 3.1 \\
\hline C & 166 & 2.9 \\
\hline D & 113 & 1.8 \\
\hline
\end{tabular}

The principle of exploiting laser beam in doping process is given by the schematic below. The laser diode is extracted from DVD reader and integrated in a specific circuit that permits to reinforce the beam and make doping of desired elements.

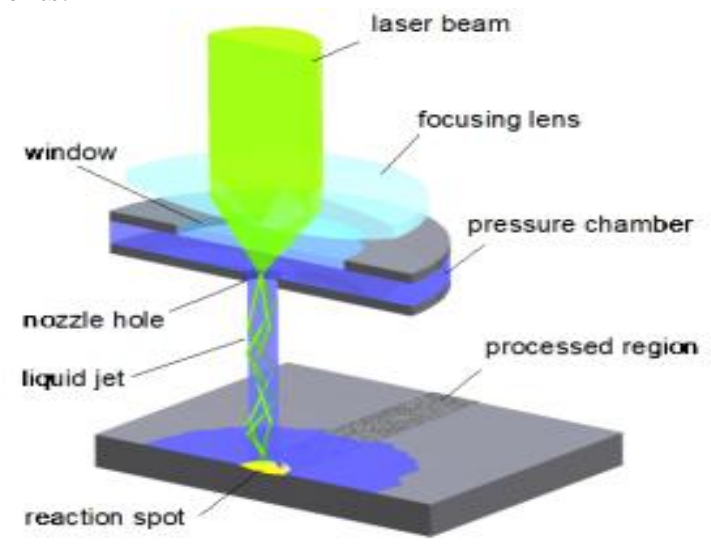

Fig. 3 .Principle of Doping process by laser beam

As known in semiconductors manufacturing the temperature variation has deep influence on junctions operation. We give here examples of impedance evolutions for different fabricated junctions while increasing temperature. Indeed, when we increase the mobility of electrons by result the impedance decrease. The curves below illustrate how our specimens behave with temperature.

Table- IV:: Resistances of samples at $\left(T=30 C^{\circ}\right)$.

\begin{tabular}{|l|l|}
\hline Samples & $\begin{array}{l}\text { Resistance } \\
\left(\mathrm{K} \Omega / \mathrm{cm}^{\wedge} 2\right)\end{array}$ \\
\hline A & 2312 \\
\hline B & 1937 \\
\hline C & 1415 \\
\hline D & 1232 \\
\hline
\end{tabular}


Table- V: Resistances of samples at $\left(T=35 C^{\circ}\right)$.

\begin{tabular}{|l|l|}
\hline Samples & $\begin{array}{l}\text { Resistance } \\
\left(K \Omega / \mathrm{cm}^{\wedge} 2\right)\end{array}$ \\
\hline A & 1781 \\
\hline B & 1542 \\
\hline C & 1075 \\
\hline D & 934 \\
\hline
\end{tabular}

Table- VI: Resistances of samples at $\left(T=40 C^{\circ}\right)$.

\begin{tabular}{|l|l|}
\hline Samples & $\begin{array}{l}\text { Resistance } \\
\left(\mathrm{K} \Omega / \mathrm{cm}^{\wedge} 2\right)\end{array}$ \\
\hline A & 1213 \\
\hline B & 875 \\
\hline C & 793 \\
\hline D & 625 \\
\hline
\end{tabular}

To compare the properties of these samples, their reflection coefficients and evolutions of electrical impedance with temperature variations. The $\mathrm{PbCl} 2$ and $\mathrm{ZnO}$ have a positive impact on reflection of light so the transparency is obtained. The evolution of electrical impedance is very significant thanks to decreasing the band gap of developed junction. Above we remark that junctions endure temperature variations so stability is established. To sum up, hence that different chemical composition to fabricate thin film and different quantities of impurities are used we obtain accepted optical, morphological and electrical characteristics. Therefore, these parameters are very interesting to take in consideration during processes of semiconductors manufacturing. After getting thin film and integrated dopants we test obtained semiconductor junction of each specimen. Thereon, the juxtaposition of two junctions constitutes our novel transistor which is a competitive type characterized by transparency and flexibility. No doubt that these performances have a significant effect on the improvement of smart devices such as glazing and others limits of newest technology. Moreover, that our junctions bear temperature increasing they are so economic according to their band gap voltage. We illustrate by the following figure depicted below.
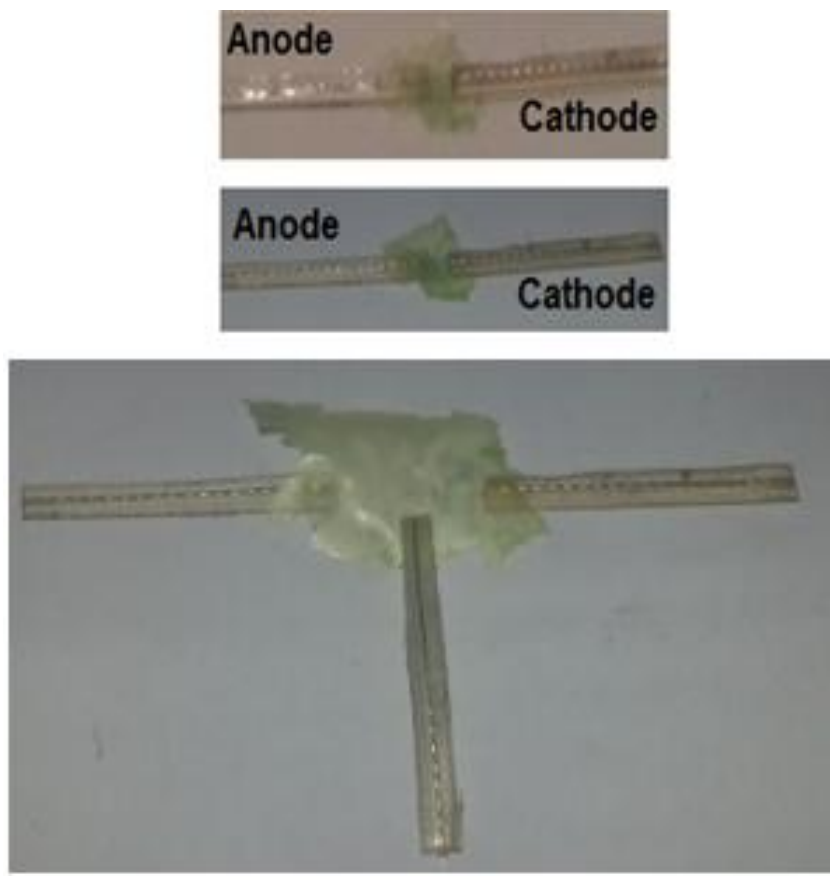

Fig. 4. Junctions and transistor connections testing.

The samples of junctions support temperature variations that reach $65{ }^{\circ} \mathrm{C}$ so their nanostructure is very lucrative. From the analysis of reflection process the specimens are competitive to their optical properties that can be used widely for intelligent semiconductors junctions. Above, the developed transistor is a promising and wonderful result that can resolve problems of glazing systems in nanotechnology.

\section{CONCLUSION}

This work has given a real alternative on how to ameliorate smart devices thanks to development of an intelligent transistor from novel semiconductor junction with high performances. It is a fruitful contribution due fabrication of innovative transistor with transparency and flexibility characteristics that improve the esthetical side in parallel to keeping of electrical high performances. Yet, the reliability of these nanostructures ensures that alloys constitute challenge contribution with thermodynamic quality due flexibility and morphological structure. The phase of built thin film is an hybrid state that plays different performances so new thinking give new possibilities in nanotechnology of semiconductors. Finally, this innovation is a concrete exploration of minerals that are a promising treasure of atlas region in Morocco by integrating these elements on fabrication processes of recent technology. We are looking forward to benefit from other derivative of $\mathrm{PbCl}_{2}$ and $\mathrm{ZnO}$ to build newest thin films and smart junctions using similar dopants ions that ensure amazing transistor quality. 


\section{REFERENCES}

1. A. Polman, M. Knight, E.C. Garnett, B. Ehrler, W.C. Sinke, Photovoltaic materials: present efficiencies and future challenges, Science 352 (2016) 307-318.

2. E.A. Lund, H. Du, W.M. Hlaing, G. Teeter, M.A. Scarpulla, Investigation of combinatorial coevaporated thin film $\mathrm{Cu} 2 \mathrm{ZnSnS} 4$ (II): beneficial cation arrangement in Cu-rich growth, J. Appl. Phys. 115 (2014) 14227-14237.

3. J.J.S. Scragg, J.K. Larsen, M. Kumar, C. Persson, J. Sendler, et al., $\mathrm{Cu}-\mathrm{Zn}$ disorder and band gap fluctuations in $\mathrm{Cu} 2 \mathrm{ZnSn}(\mathrm{S}, \mathrm{Se}) 4$ : theoretical and experimental investigations, Phys. Status Solid. 253 (2015) 247-254.

4. A. Tang, Z. Li, F. Wang, M. Dou, J. Liu, J. Ji, Y. Song, Electrodeposition mechanism of quaternary compounds $\mathrm{Cu} 2 \mathrm{ZnSnS4}$ effect of the additives, Appl. Surf. Sci. 427 (2018) 267-275.

5. N.A. Shvab, V.D. Litovchenko, L.M. Rudkovskaya, Mechanism of reduction of thiosulfate ions on the cathode, Russ. J. Appl. Chem. 80 (2007) 1852-1855

6. Y. Leng, Materials characterization: introduction to microscopic and spectroscopic methods, Wiley, Weinheim, Germany, 2013.

7. M. Guo, X. Zhu, H. Li, Comparative study of $\mathrm{Cu} 2 \mathrm{ZnSnS} 4$ thin film solar cells fabricated by direct current and pulse reverse co-electrodeposition, J. Alloys Compd. 657 (2016) 336-340.

8. B. Unveroglu, G. Zangari, Towards phase pure Kesterite CZTS films via $\mathrm{Cu}-\mathrm{ZnSn}$ electrodeposition followed by sulfurization, Electrochim. Acta 219 (2016) 664-672.

9. L. Atourki, E.H. Ihalane, H. Kirou, K. Bouabid, A. Elfanaoui, et al., Characterization of nanostructured $\mathrm{ZnO}$ grown by linear sweep voltammetry,

Sol. Energy Mater. Sol. Cells 148 (2016) 20-24.

10. C. Gougaud, D. Rai, S. Delbos, E. Chassaing, D. Lincot, Electrochemical studies of one-step electrodeposition of $\mathrm{Cu}-\mathrm{Sn}-\mathrm{Zn}$ layers from aqueous electrolytes for photovoltaic applications, J. Electrochem. Soc. 160 (2013) D485-D494.

11. J. Tao, J. Liu, L. Chen, H. Cao, X. Meng, et al., $7.1 \%$ efficient co-electroplated $\mathrm{Cu} 2 \mathrm{ZnSnS} 4$ thin film solar cells with sputtered CdS buffer layers, Green Chem. 18 (2016) 550-557.

12. J. Tao, L. Chen, H. Cao, C. Zhang, J. Liu, et al., Co-electrodeposited $\mathrm{Cu} 2 \mathrm{ZnSnS} 4$ thin-film solar cells with over $7 \%$ efficiency fabricated via fine-tuning of the $\mathrm{Zn}$ content in absorber layers, J. Mater. Chem. A 4 (2016) 3798-3805.

13. D. Liedekerke, Marcel, Zinc oxide (zinc white): Pigments, inorganic, Ullmann's Encyclopdia of Industrial Chemistry, Wiley-VCH, Weinheim, 2006

14. J. Li, D.B. Mitzi, V.B. Shenoy, Structure and electronic properties of grain boundaries in earth-abundant photovoltaic absorber Cu2ZnSnSe4, ACS Nano 5 (2011) 8613-8619.

15. K. Bouabid, M. Nya, A. Ihlal, Effects of Na2SO4 on the optical and structural properties of $\mathrm{Cu} 2 \mathrm{ZnSnS} 4$ thin films synthesized using co-electrodeposition technique, Opt. Mater. 75 (2018) 471-482.

16. H. Battez, A. Gonzalez, R. Viesca, J. Fernandez, J. Diazfernandez, et al., $\mathrm{CuO}, \mathrm{ZrO} 2$ and $\mathrm{ZnO}$ nanoparticles as antiwear additive in oil lubricants, Wear. 265 (2008) 422-428.

17. A.A. Dubale, A.G. Tamirat, H.M. Chen, T.A. Berhe, C.J. Pan, et al., A highly stable $\mathrm{CuS}$ and $\mathrm{CuSePt}$ modified $\mathrm{Cu} 2 \mathrm{O} / \mathrm{CuO}$ heterostructure as an efficient photocathode for the hydrogen evolution reaction, $\mathrm{J}$. Mater. Chem. A 4 (2016) 2205-2216.

18. Ü. Özgür, Alivov, Y.I. Liu, C. Teke, A. Reshchikov, et al., A comprehensive review of $\mathrm{ZnO}$ materials and devices, J. Appl. Phys. 98(4) (2005) 041301:1-103.

19. A. Fairbrother, X. Fontane, V. Izquierdo-Roca, M. Espíndola-Rodríguez, S. Lopez-Marino, et al., On the formation mechanisms of Zn-rich Cu2ZnSnS4 filmsprepared by sulfurization of metallic stacks, Sol. Energy Mater. Sol. Cells 112 (2013) 97-105.

20. A. Fairbrother, X. Fontane, V. Izquierdo-Roca, M. Espíndola-Rodríguez, S. Lopez-Marino, et al., On the formation mechanisms of Zn-rich Cu2ZnSnS4 films prepared by sulfurization of metallic stacks, Sol. Energy Mater. Sol. Cells 112 (2013) 97-105.[21] B.G. Kutchko, A.G. Kim, Fly ash characterization by SEM-EDS, Fuel 85 (2006) 2537-2544.

21. M.C. Meyer, P. Austin, P. Tropper, Quantitative evaluation of mineral grains using automated SEM-EDS analysis and its application potential in optically stimulated luminescence dating, Radiat. Meas. 58 (2013) 1-11.

22. J. Chininis, P.J. Whiteside, H.K. Hunt, Metal-clad waveguide characterization for contact-based light transmission into tissue, Proc. SPIE, Photon. Therap. Diagnos. 12 (2016) 968915.
23. S. Zhu, A.W. Yu, D. Hawley, R. Roy, Frustrated total internal reflection: A demonstration and review, Am. J. Phys. 54 (1986) 601-607.

24. M. Hamdi, A. Oueslati, A. Lafond, C. Guillot-Deudon, F. Hlel, Structural, morphological and electrical properties of Cu2ZnSn1-xSixS4 ( $\mathrm{x}=0.8, \mathrm{x}=1)$ for solar-cells applications, $\mathrm{J}$. Alloys Compd. 674 (2016) 73-81. 